\title{
The future of reference III: A response
}

\author{
By Cynthia A. Kehoe
}

\author{
Librarian, Balcones Library Service Center \\ University of Texas at Austin
}

I would like to focus on two types of problems we must deal with in moving towards the library as concept, with the electronic information system as a primary medium and artificial intelligence as a major tool in aiding user access.

We face both pragmatic and conceptual problems. The primary conceptual problem has to do with the nature of reference. One characteristic of the reference process is that patrons are asking questions about something unknown to them, making it difficult to express a question clearly. The patron must often talk around the problem, just as the description of a donut hole relies on the description of the donut surrounding it. The identification of an information need must often be interactive; problems are clarified through dialogue. Users frequently leave out the context of a question, or phrase their questions based on assumptions about possible sources or a likely solution.

Robert Taylor, in his classic article of 25 years ago on information seeking and question negotiation, spoke of four levels of information need - the visceral or unconscious, the conscious but vaguely defined, the formalized, and the compromised need. ${ }^{1}$ The compromised need is the one often brought to an information system or expressed to a librarian. It has been molded to fit the information system, and may bear little resemblance to the original information need. One task of the reference librarian is to help determine what the conscious information need of the user is.

Expert systems are usually based on a major assumption that may be false in many reference situations- that the question posed by the user is a close approximation of the actual information need. The system may have a procedure for narrowing a request, but rarely is there a means of completely reshaping the question. There is little means for aiding the user to move from a compromised query to the conscious information need. Reference librarians all have favorite anecdotes of users whose initial questions bore little resem-

${ }^{1}$ Robert S. Taylor, "The Process of Asking Questions," American Documentation 13 (1962): 391-396. blance to the actual need that was eventually identified. Expert systems may eventually be able to cope with such situations, but they are not there yet and I do not expect them to be for some time.

Part of the new vision of the library as concept includes interaction between patrons and reference librarians that is much less often face-to-face. This prospect reminds me of an anecdote about Xerox PARC, the research center which does a lot of work in office automation. A number of years ago, the Xerox PARC computer scientists designed a glitzy new computer system for the office, incorporating all the latest computer technology and developing some new ones, that could do all kinds of wonderful things. The Xerox PARC staff was very excited, and eager to demonstrate it in another meeting. The system was placed in a Xerox corporate office, and it failed. Nobody used it. When the research staff examined why, they found that it was because the system, while exciting to technologists, bore little relation to the way people work.

Xerox, being smart, hired psychologists and anthropologists and specialists in organizational behavior as part of their research teams, and the next generation of products was much more successful.

What does this have to do with libraries? The possibility of electronic reference work is exciting to many, but it doesn't yet appear to fit in with how many of our patrons use libraries. Part of the barrier is simply lack of knowledge among patrons about the possibilities. It still surprises many people that they can call a library and ask a reference question over the phone. But part of the barrier is that use of these systems requires a change in behavior for many people that hasn't been demonstrated to them to have a strong enough payback to warrant the change.

The library is still, for many people, a place to go because of the importance patrons place on interaction with the staff and immediate access to a wide range of materials. Even in a library service unit, such as the one in which I work, with lots of technology and almost no collection, most patrons still come to the "library" rather than contact us by other means in order to request materials available elsewhere. Patrons prefer to talk with a person, primarily for reassurance, I suspect. They want to 
be sure that they've given the staff all the necessary information for a request, to ask questions, and to allow us to ask questions. The process is highly interactive, personalized, and immediately responsive.

We may eventually design avenues of access to the library and its contents in addition to face-toface that patrons will regularly use, but this will be a slow process. We will need to utilize the research we already have about information-seeking behavior, as well as gather new data on how that behavior changes as new technologies become available, in order to design successful access points. We also need to examine what patrons think will improve the library. They often seem much less interested in new means of access than in whether we are effective at our present services. How fast can you put what they want in their hands?

Many visions of the library's future are primarily technological, and do not give us any time frame for their realization. Some of the technologies discussed are available now (for a price); others may not be available for 20 years. The primary pragmatic problems we face have to do with the resources needed to develop our electronic libraries. Project costs to develop a small expert system (of only 50 to a few hundred rules) start at $\$ 25,000$, and take the equivalent of more than .25 person years of the programmer alone. ${ }^{2}$ To design an expert system to help answer ready reference questions, an experienced $\mathrm{AI}$ programmer would need to spend at least ten hours per week for a year, working with a reference librarian who would need to find three to five hours per week for that same period. In addition, to support this system, we would have to purchase workstations on which to run it. If we want to provide dial-up access, we may need to work with the campus computer center to expand networking capabilities-again for an additional cost. And the program and equipment would need to be maintained and updated. In an era in which library budgets are shrinking, and personnel budgets often seem to us particularly hard hit, we must seek large amounts of additional funding to build our new information systems.

Expert systems in business can rarely be justified on the basis of savings in the number of employees. The savings come from elsewhere-often more accuracy in decision making saves the company money. The benefit for libraries will not be as easily demonstrated. These systems are not likely to result in fewer staff, though there may be some shifting of duties. For a reference librarian to spend 200 hours over the course of a year as part of an AI

${ }^{2}$ Paul Harmon et al., Expert Systems Tools and Applications (New York: John Wiley \& Sons, Inc., 1988): 184. design team is 200 hours away from something else. Academic libraries have been retrenching in various ways for a number of years, and it is becoming increasingly difficult to find trade-offs and tasks to give up in order to allow staff to take on new projects.

A major role of librarians in a reference room is instruction in the use of particular tools. It has been suggested that we should make more of this instruction computer-based. Aside from the issue that such instruction is rarely in a vacuum, and there is often a broader information need to be addressed, the cost of designing a one-hour computer-based training program is high. The primary expense again is personnel. It takes about 200-250 hours of development to produce one hour of computer-based instruction. ${ }^{3}$

This is not to advocate refusing to design these systems because we cannot afford them, but it is a reminder that we will need to work hard to justify our projects to funders, to increase the level of funding, and to find it from new sources if we are to succeed. Smaller academic libraries in particular will face serious difficulties in providing these tools.

In the transition towards a more electronic library, we may find it increasingly hard to cope with patron demands-particularly as we provide increased access to all kinds of materials in citation form, but do not provide electronic delivery of the full text as quickly. Faculty are not necessarily willing to face trade-offs between buying materials and providing electronic access during this period of change. Libraries have already found that having an online catalog often leads to increased circulation-especially in areas that were not as accessible through card catalogs, such as government documents and special collections. Adding end-user searching capabilities, such as CD-ROM in the reference room, increases the demands on reference staff, and increases the number of items requested through interlibrary loan. There is also a greater need for instruction in the various new computer-based information systems.

One of the side effects of electronic information systems is the greater potential for information overload. Many filters (good and bad) disappear in the electronic environment. Librarians will need to work with faculty to teach undergraduates how to better evaluate and filter information.

The proliferation of computer-based information systems continues to be much more rapid than the improvement in search interfaces. Standardization of interfaces is slow. AI will help out here eventually. But again, this is going to come slowly,

${ }^{3}$ Estimate by Dr. Patricia Smith, Associate Professor, Department of Curriculum and Instruction, University of Texas at Austin. 
and the transition may be rocky. These information systems are not easy to use. In a study in which Stanford undergraduates were briefly trained to use an online catalog with Boolean capabilities, one-third could not use it. ${ }^{4}$ And full-text databases are more difficult to use than such catalogs. One of the most common problems is in how to formulate a search query - the point at which AI has the least help to offer at this time. Part of the difficulty lies in the fact that most patrons use these systems infrequently, and therefore are not able to remember all the necessary commands and strategies of the more complex systems from session to session. This tends to discourage casual users.

Online vendors have reported increasing numbers of passwords allotted to end-users. But the libraries which keep track of the searching (and the bills) report that these systems generate initial enthusiasm, but that only a small number of patrons continue to use them. Some of the new information technologies, such as online catalogs, do generate immediate and continued interest among patrons, but not all information systems have been as successful.

In order to improve the search interfaces of these systems, a great amount of research still needs to be done. There are not a lot of prototypes resulting from information retrieval research that are obviously better than current systems, especially for a range of user system and subject expertise, and just waiting to be implemented. Librarians (and other knowledgeable library staff) should be involved in research and development projects, but many of the efforts that are needed will require a significant investment on the part of libraries and other agencies, in staff time and other resources. The research needs open up many possibilities for cooperative efforts in applied research among libraries, with other departments in the university, and with other agencies such as publishers. Such cooperative efforts impose their own constraints.

As we move towards a greater use of technology, we also must invest more strongly in our staffs. Staff members need training in the use of computers and information technologies. Are all staff able to use microcomputers and the online catalog? Is the reference staff expected to try each new CD-ROM for an hour or so when it first arrives? Or do reference librarians feel guilty if they're trying a new $\mathrm{CD}$ and a patron wants to use it?

In addition to investing in our staff both through in-house training and providing release time and funding for training outside the library, we also have to invest in technology for the staff to use. It is difficult to help patrons with equipment we rarely

${ }^{4}$ Christine Borgman, The User's Mental Model of an Information Retrieval System: Effects on Performance (dissertation, Stanford University, 1984). have access to ourselves. Part of what we know from studies of the diffusion of innovations is that an important part of getting patrons to accept a new technology is to make the staff comfortable with it-including the less obvious staff members. In an academic library, one means of ensuring acceptance of new computer tools is to teach your student staff how to use them (when they're not teaching you). Their enthusiasm in other settings is a great benefit.

As we incorporate information technologies, we must not forget that it will be years yet before everyone has a computer at home, with telecommunications capabilities, and before nearly all patrons are computer literate. The number of nontraditional college students has been on the increase for many years. In addition, the frequently quoted statistics showing that more and more elementary and high schools have computers are misleading. The number of schools owning microcomputers is quite high; the number of computers in each school is still low. One-third of all public schools have less than ten microcomputers. ${ }^{5}$ The students graduating from high school in the next few years will have vast differences in their computer experiences. Libraries may have to play several roles in maintaining equity providing adequate computer access to their information tools in the library, and helping to train students who do not yet have the necessary skills to use the information technologies. The other major aspect of equity is cost. Can we ask undergraduates to help pay for these systems and, if so, in what form should the payment be?

As we attempt to utilize more and more computer-based technologies, libraries are going to have to become more aggressive in seeking funding. Equipment is expensive, and adding it does not necessarily result in great savings elsewhere. More libraries will need to have a grants specialist on their staff, who is given both adequate time and training to pursue funding. Grant money, however, is finite and project-oriented. Library administrators will have to work harder than ever to solicit moneys from university administrators and legislatures that have often been cutting library funding for years. While libraries can sometimes get onetime start-up funds for flashy computer products for patrons, the real task ahead may be to solicit maintenance and updating funds for these products, and funds for equipment for the staff, much less popular causes.

I have suggested problems in two areas-issues related to the design and use of information technologies, and problems caused by the need for additional resources, including support for our

${ }^{5}$ The Electronic Directory of Education (Market Data Retrieval, 1989). Database available through Dialog Information Services, Inc. 
staffs. I do not intend to suggest that we should not pursue some of these projects, although we must make our choices carefully. Artificial intelligence is not going to solve many problems for us in the next five to ten years, and it is difficult to predict its impact over thirty years. Our tasks will not be easy, and we will not reach our goals as quickly as we might wish.

\section{The future of reference III: Another response}

\section{By Dennis Trombatore}

\author{
Librarian, Geology Library \\ The University of Texas at Austin
}

While I found Pat Molholt's presentation entertaining and challenging, I would like to remind everyone that we are talking about the concept of libraries in the context of universities where, if I can paraphrase, we practice the willing suspension of profit and loss in the hope of having an effect on people's lives, to transmit understanding through teaching, and to inquire into the nature of things. The university is not McDonald's, Chevron, or IBM, and though there is a mythology of the university, described by Anne Woodsworth, Pat Molholt, et al. in their 1989 article as "in mission, character, and organizational structure ... essentially a medieval institution,"1 and that mythology may have been deeply altered by big professions, big sports, big research, big government, and big enrollments, I believe it is too soon to replace the library, the so-called heart of the mythical university, with a Jarvik-7.

In spite of Pat Molholt's subtle efforts to downplay the significance and usefulness of print collections while skillfully persuading us of the allure and irresistible vitality of artificial intelligence (AI) systems, the fact is that no matter what technological mix we end up being able to afford in university libraries, the key to the information future is human-based services delivered by a sufficient number of people who care and people who hustle to get the job done right the first time.

At the 1978 LITA Conference on Closing the Card Catalog, Hugh Atkinson, then of Ohio State, also spoke about walls- he predicted that online library catalog systems would destroy traditional physical and social work patterns in libraries, in effect allowing workers and work to be distributed in a way that would unify library departments at the same time that it increased their autonomy and

'Anne Woodsworth et al., "The Model Research Library: Planning for the Future," Journal of Academic Librarianship 15 (July 1989): 132-138. improved services. ${ }^{2}$ Atkinson described these work groups as "tribes" of about a dozen people. In effect, this amounts to a reinvigoration of the branch library concept (something that has in fact happened) where, rather than splitting off and compartmentalizing print from electronic systems, collection development from technical services, or reference from administration, these necessary segments of an information delivery system are integrated around the mutual online catalog files now available to us. Meanwhile we in branch libraries, who wear all these hats, can ply our trade where it counts-footsteps away from our customers.

I'd like to remind everyone that all the hullabaloo about access over acquisition is the sad outgrowth of physical and fiscal exigency, and that the yearning for global interconnectivity is just another run at the same old wish to have everything close at hand. Yet, access without delivery is suicide. To illustrate that, let me ask you to substitute the term "microform" for "AI" in the access provision model. We already provide lots of access on microform, but people confound us by refusing to accept it. Why? Because we refuse to put muscle behind delivery. In order to save money most libraries offer too few printers, printers that are poorly designed, that cost too much when they do work, and that generally give a lousy product.

The costs of real AI systems, with serious access and delivery potential, would destroy us, so we will settle for what we can afford-something between that old magic eight-ball toy and a thought policeman-all the while asking ourselves why no one is ever satisfied.

${ }^{2}$ Hugh C. Atkinson, "The Impact of Closing the Catalog on Library Organization," in Closing the Catalog: Proceedings of the 1978 and 1979 Library and Information Technology Association Institutes, ed. by D.K. Gapen and B. Juergens (Phoenix: Oryx Press, 1980): 123-133. 